American Journal of Infectious Diseases 4 (1): 10-17, 2008

ISSN 1553-6203

(C) 2008 Science Publications

\title{
High Case-Fatality Rate of Adults with Dengue Hemorrhagic Fever During An Outbreak In Non-Endemic Taiwan: Risk Factors For Dengue-Infected Elders
}

${ }^{1}$ Ching-Chuan Liu, ${ }^{2}$ Kao-Jean Huang, ${ }^{3}$ Mei-Chih Huang, ${ }^{4}$ J.-J. Lin, ${ }^{5}$ S.-M. Wang, ${ }^{6}$ Jen-Jou Liu, ${ }^{7}$ Jih-Jin Tsai, ${ }^{8}$ Jyh-Hsiung Huang, ${ }^{2}$ Yee-Shin Lin, ${ }^{2}$ Hsiao-Sheng Liu, ${ }^{9}$ Trai-Ming Yeh and ${ }^{2}$ Huan-Yao Lei

${ }^{1}$ Departments of Pediatrics, ${ }^{2}$ Microbiology and Immunology, ${ }^{3}$ Nursing, ${ }^{4}$ Basic Medical Sciences, ${ }^{5}$ Emergency Medicine and ${ }^{9}$ Medical Technology, College of Medicine, National Cheng Kung University, Tainan, ${ }^{6}$ Department of Infectious Diseases, Chang Gung Memorial Hospital-Kaohsiung Medical Center, Kaohsiung, ${ }^{7}$ Department of Internal Medicine, Kaohsiung Medical University Hospital, Kaohsiung, ${ }^{8}$ Center for Disease Control, ${ }^{9}$ Department of Health, Taipei, Taiwan

\begin{abstract}
In 2002, a dengue outbreak occurred in Taiwan with 5336 confirmed cases, 242 DHF and 21 death, the case fatality rate reached $8.7 \%$ (21/242). The demographic data of these age-specific dengue patients showed that dengue virus infection caused symptom primarily occurred in adults. A comparative analysis of clinical and laboratory data for DF, DHF/DSS and fatal DSS found that high fatality from dengue infection was associated with the following patient conditions: (1) age above 55 years, (2) underlying diseases with hypertension, chronic renal insufficiency, or diabetes, (3) abnormal thrombocytopenia, APTT and PT prolongation, low hematocrit $(<30 \%)$ and leukocytosis, (4) abnormal elevation of AST, ALT and BUN. In a non-endemic area like Taiwan, dengue should be considered as an adult infectious disease and the dengue-infected elders will have higher morbidity or mortality.
\end{abstract}

Key words: Dengue disease, risk factors, elder, morbidity, mortality

\section{INTRODUCTION}

Dengue virus infection has an iceberg characterization. Most cases are symptomless, followed, in increasing rarity, by undifferentiated fever, dengue fever (DF) and life-threatening dengue hemorrhagic fever/dengue shock syndrome (DHF/DSS). DF is an acute febrile illness with symptoms of headache, retro-orbital pain, myalgia, arthralgia, rash, leukopenia and mild thrombocytopenia. Biphasic fever and rash are the most characteristic features of classic dengue fever. Although symptoms usually resolve after 5 to 7 days, there is a possibility of progression to DHF, an acute vascular permeability syndrome accompanied by abnormalities in hemostasis ${ }^{[1,2]}$. The clinical features include plasma leakage, bleeding tendency and liver involvement. Capillary leakage develops rapidly over a period of hours, near or at the end of the febrile period when the symptoms of classic DF resolve. Pleural effusion, ascites and hemoconcentration are indicative of intravascular volume loss. The hemorrhagic manifestations range from a positive tourniquet test to spontaneous bleeding from the nose or the gastrointestinal tract. Hemoconcentration and marked thrombocytopenia are two major characteristic features of DHF/DSS. DHF/DSS is thus a very dynamic systemic illness and clinical manifestations of dengue virus infection progress quickly. At defervescence, the stage when the patient's condition becomes unfebrile and temperature falls, there is a turning point. In the case of DF, this point marks the beginning of recovery, while in the case of DHF, this point can mark the start of a rapid progress to shock, if patients do not receive timely intravascular fluid resuscitation. Once the shock is prolonged to an irreversible stage, it can be fatal. When appropriate intravenous fluid replacement is provided, the DHF/DSS patients will recover in one or two day with no disease sequelae ${ }^{[3]}$.

$\mathrm{DF} / \mathrm{DHF}$ is the most important arboviral disease of humans, occurring in tropical countries of the world where $>2.5$ billion people are at risk of infection. DHF is primarily a disease of children, although the age distribution of DHF cases has changed progressively and with geographic difference ${ }^{[4-6]}$. In 1998, major epidemics occurred throughout Asia and the Americas,

Corresponding Author: Huan-Yao Lei, Department of Microbiology and Immunology, College of Medicine, National Cheng Kung University, Tainan, Taiwan, Republic of China 
with $>1.2$ million cases of DF/DHF reported to the World Health Organization (WHO). It is estimated that between 50 and 100 million cases of DF and several hundred thousand cases of DHF occur each year, depending on the epidemic activity ${ }^{[7,8]}$. The case fatality rate of DHF/DSS in general is lower than $1 \%$ on average $^{[9]}$. However, in 2002, out of a total of 5336 confirmed local cases of dengue patients reported in the Kaohsiung Area of Taiwan ${ }^{[10-13]}, 242$ of these were DHF and led to 21 reported DHF/DSS caused deaths. In contrast to findings in other endemic area, all the fatal cases were adults. The case-fatality rate of DHF was $8.7 \%$ (21/242), higher than that in children. The analysis of the clinical data among the adult cases of DF, DHF/DSS and fatal DSS showed association with several risk factors with regard to the severity of DHF or death. The elders with underlined diseases are more susceptible to death after dengue virus infection.

\section{MATERIALS AND METHODS}

Study subjects: In total, 155 dengue patients in the Kaohsiung 2002 outbreak with laboratory-confirmed DF or DHF/DSS were enrolled in the study, including 21 fatal, 84 DHF/DSS and 50 DF cases. Dengue infections were confirmed by RT-PCR or viral envelope and membrane (E/M)-specific capture IgM and IgG ELISA at the Branch Office IV, CDC, Taiwan. According to the criteria of the WHO, patients were divided into four grades, as non-shock DHF (grades I, II) and DSS (grades III, IV) ${ }^{[14]}$. Clinical information was collected retrospectively on these patients that reported to the Center for Diseases Control (CDC), Taiwan. The patients with DHF/DSS were hospitalized. The day of the onset of fever higher than $38^{\circ} \mathrm{C}$ is used as primary index and defined as fever day 0 .

Blood samples and laboratory studies: Sequential blood samples, one acute and two follow up were collected from some patients in this study. Plasma was harvested within $30 \mathrm{~min}$ at $37^{\circ} \mathrm{C}$ of venipuncture from EDTA-anti-coagulated venous blood sample and stored at $-70^{\circ} \mathrm{C}$ until analysis. The results of the laboratory investigations that were performed as part of routine clinical care were also recorded from the case-sheets. These included hematological and biochemical investigations and bacterial culture of blood. The earliest blood sample we could collect in this study was at day 3 of fever. Dual analyses of E/M-specific capture IgM and IgG ELISA and NS1 serotype-specific IgG ELISA were used to differentiate primary and secondary dengue virus infections as previously described ${ }^{[15]}$.
Statistical analysis: Statistical analyses were done by use of SPSS for Windows (version 11.0; SPSS Inc., Chicago, IL, USA), including Fisher's exact test for categorical variables, the two-sample t-test and MannWhitney $U$ test for continuous variables and multivariate logistic regression analysis. A value of $\mathrm{p}<0.05$ was considered statistically significant.

\section{RESULTS}

Epidemiology and demographic data. A largest dengue outbreak occurred in southern Taiwan in 2002 with a total of 5336 laboratory-confirmed cases ${ }^{[10]}$. The affected areas were primarily in Kaohsiung City, Fengsung City and Pingtung City with a population around 2,233,000 in an area of $353 \mathrm{~km}^{2}$. This epidemic was caused by dengue virus serotype 2 . There were 242 cases of DHF/DSS, amounting to $4.5 \%$ of the total 5336 cases. However, 21 patients died with the case fatality rate of DHF reaching as high as $8.7 \%$ (21/242). Based on retrospective review of the medical records on clinical information and laboratory data, most of the dengue infected persons were adults. The age-specific prevalence of DF, DHF/DSS and fatal DSS showed that the age of DF peaked at 50 years while that of the DHF increased to 60 years of age. Among the 21 fatal cases, $16(76 \%)$ of them were older than 55 years of age (Fig. 1a-c). When the population of the affected area was taken into account, the age-specific prevalent rate was recalculated as Fig. 1d-f. The pattern of age distribution is similar, but is more apparent that dengue virus infection caused symptom primarily occurred in adults. Dengue-infected elders would develop more severe DHF/DSS or even death. The male to female ratio did not differ among DF, DHF/DSS and fatal cases (data not shown). For the symptoms and signs after dengue virus infection, DHF/DSS showed significantly more myalgia, abdominal pain, bone pain, arthralgia, GI bleeding, pleural effusion, melena, ascites and gum bleeding than DF while the fatal cases had a significantly higher ratio of conscious disturbance, GI bleeding, shock/prolonged shock than non-fatal one as expected (Table 1). The clinical manifestations in our 2002 dengue patients did not substantially differ from those of the classical dengue pattern, except for a distinct difference in the age-specific prevalent rate and also a higher than expected mortality among the dengue-infected patients. In a non-endemic Taiwan, dengue should be considered as an adult infectious disease and the dengue-infected elders will have higher morbidity or mortality.

Underlying diseases and laboratory analysis. Since most of the dengue patients were above 50 years of age, 


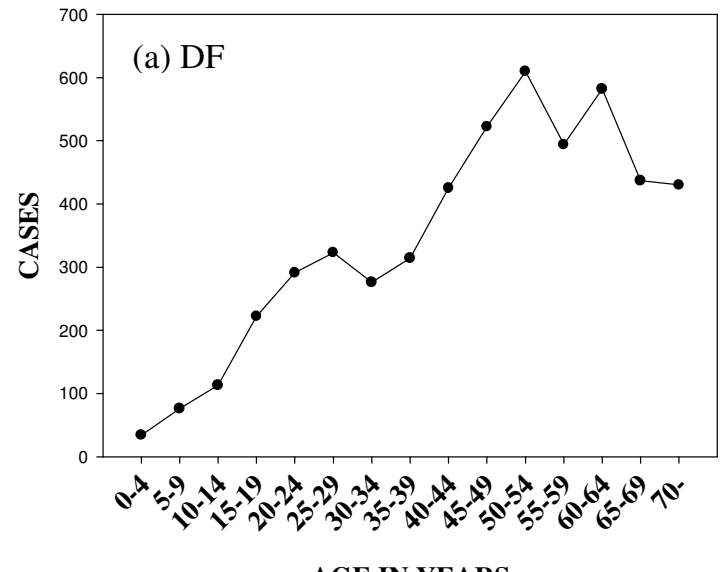

AGE IN YEARS

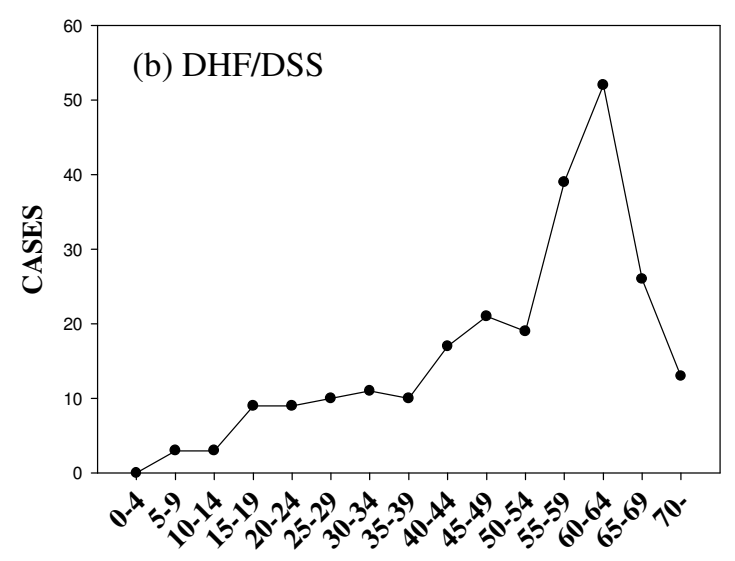

AGE IN YEARS

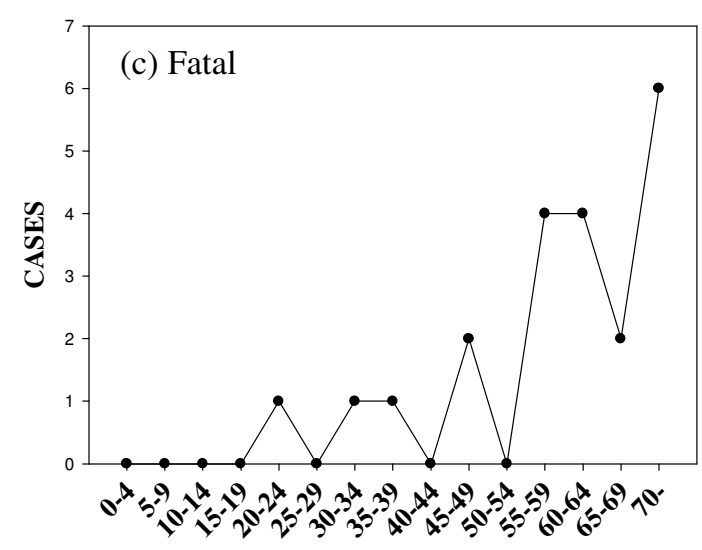

AGE IN YEARS

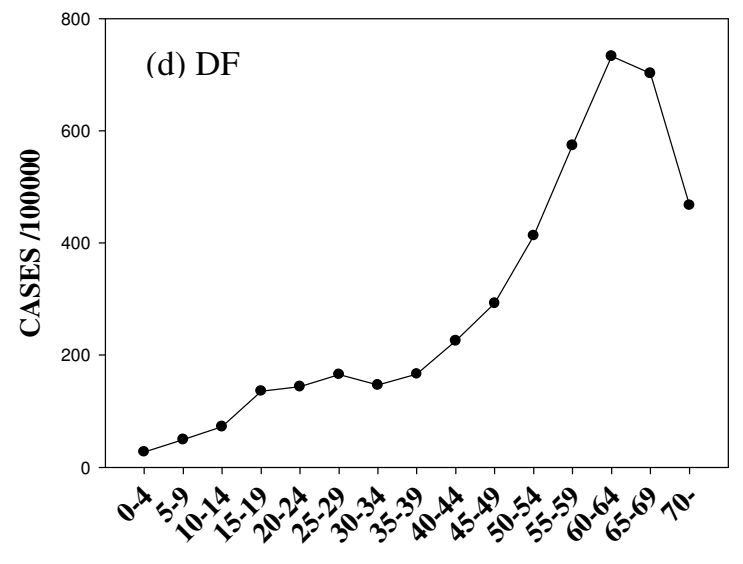

Age in years

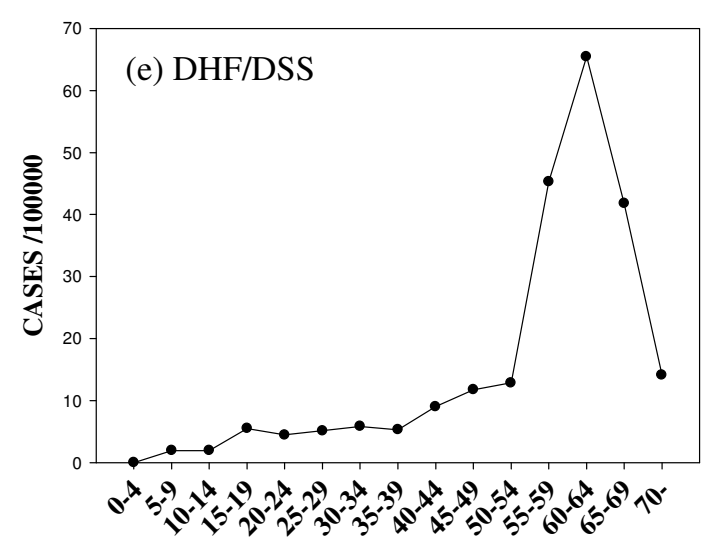

Age in years

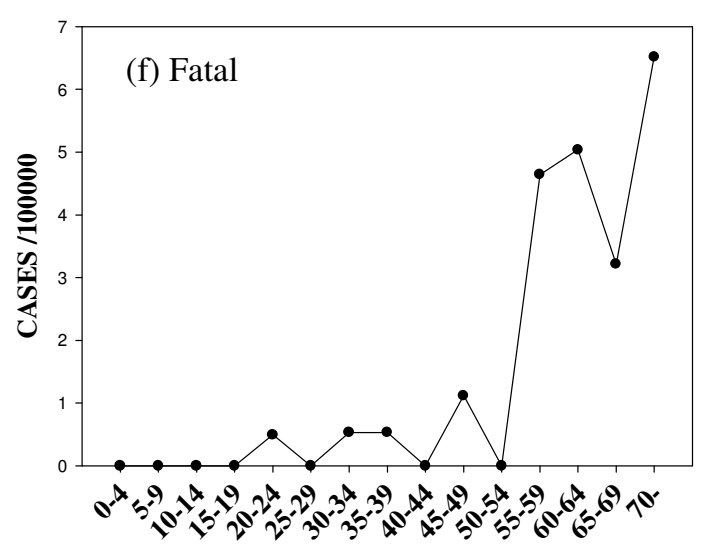

Age in years

Fig. 1: Age-specific prevalent rate of DF, DHF/DSS and fatal DSS in 2002 Kaohsiung dengue outbreak. A total of 5336 dengue-infected patients with 242 DHF and 21 fatal cases was plotted against the age of 5 years 
Am. J. Infect. Dis., 4 (1): 10-17, 2008

Table 1: The percentage of symptoms and signs in patients with DF, DHF/DSS and fatal cases

\begin{tabular}{|c|c|c|c|c|c|c|c|}
\hline Symptom/Sign & $\begin{array}{l}{ }^{\mathrm{a}} \mathrm{DF}(\%) \\
\mathrm{N}=50\end{array}$ & $\begin{array}{l}{ }^{6} \text { DHF/DSS } \\
(\%) \mathrm{N}=84\end{array}$ & $\begin{array}{l}{ }^{\mathrm{c}} \text { Death case } \\
(\%) \mathrm{N}=21\end{array}$ & $a-b-c p^{\#}$ & $\mathrm{a}-\mathrm{b} \mathrm{p}^{\#}$ & $\mathrm{a}-\mathrm{c} \mathrm{p}^{\#}$ & $\mathrm{~b}-\mathrm{c} \mathrm{p}^{\#}$ \\
\hline Fever & 98.0 & 98.1 & 95.2 & NS & NS & $\mathrm{NS}$ & NS \\
\hline Myalgia/malaise & 55.1 & 80.7 & 77.8 & 0.006 & 0.002 & NS & NS \\
\hline Abdominal pain & 28.6 & 55.0 & 68.4 & 0.002 & 0.003 & 0.003 & NS \\
\hline Anorexia & 58.0 & 75.3 & 64.3 & NS & NS & NS & NS \\
\hline Cons. disturbance & 0.0 & 2.4 & 90.5 & $<0.001$ & NS & $<0.001$ & $<0.001$ \\
\hline Bone pain & 53.1 & 75.0 & 47.4 & 0.011 & 0.01 & NS & 0.018 \\
\hline Arthralgia & 20.0 & 41.5 & 37.5 & 0.058 & 0.018 & NS & NS \\
\hline Headache & 54.3 & 65.8 & 38.9 & NS & NS & NS & 0.036 \\
\hline Vomiting & 18.8 & 28.4 & 31.3 & NS & NS & NS & NS \\
\hline Diarrhea & 28.0 & 25.0 & 41.7 & NS & NS & NS & NS \\
\hline Nausea & 42.0 & 58.1 & 43.8 & NS & NS & NS & NS \\
\hline GI bleeding & 18.0 & 53.0 & 89.5 & $<0.001$ & $<0.001$ & $<0.001$ & 0.003 \\
\hline Petechiae & 66.0 & 75.0 & 60.0 & NS & NS & NS & NS \\
\hline Pleural effusion & 4.1 & 61.5 & 52.6 & $<0.001$ & $<0.001$ & $<0.001$ & NS \\
\hline Melena & 18.0 & 46.3 & 61.1 & 0.001 & 0.001 & 0.001 & NS \\
\hline Rash & 60.0 & 45.5 & 50.0 & NS & NS & NS & NS \\
\hline Ascites & 6.0 & 43.8 & 35.0 & $<0.001$ & $<0.001$ & 0.002 & NS \\
\hline Epistaxis & 4.0 & 6.3 & 16.7 & NS & NS & NS & NS \\
\hline Gum bleeding & 23.4 & 38.8 & 31.6 & NS & $<0.001$ & NS & NS \\
\hline Hemoptysis & 2.2 & 10.0 & 27.8 & 0.09 & NS & 0.002 & 0.045 \\
\hline Hematuria & 6.1 & 12.7 & 18.2 & NS & NS & NS & NS \\
\hline Shock & 0.0 & 4.8 & 100.0 & $<0.001$ & NS & $<0.001$ & $<0.001$ \\
\hline Prolong shock* & 0.0 & 0.0 & 90.5 & $<0.001$ & NS & $<0.001$ & $<0.001$ \\
\hline
\end{tabular}

*: Prolong shock: shock $>6 \mathrm{~h}, \#$ : Chi-square test

Table 2: The underlying diseases in patients with DF, DHF/DSS and fatal cases

\begin{tabular}{|c|c|c|c|c|c|c|c|}
\hline & $\begin{array}{l}{ }^{\mathrm{a}} \mathrm{DF}(\%) \\
\mathrm{N}=50\end{array}$ & $\begin{array}{l}{ }^{\mathrm{b}} \mathrm{DHF} / \mathrm{DSS} \\
(\%) \mathrm{N}=84\end{array}$ & $\begin{array}{l}{ }^{{ }^{c} \text { Death case }} \\
(\%) \mathrm{N}=21\end{array}$ & $a-b-c p^{\#}$ & $\mathrm{a}-\mathrm{b} \mathrm{p}^{\#}$ & $a-c p^{\#}$ & $\mathrm{~b}-\mathrm{c} \mathrm{p}^{\#}$ \\
\hline \multicolumn{8}{|l|}{ Age (year) } \\
\hline Mean $\pm \mathrm{SD}^{@}$ & $57.1 \pm 12.9$ & $51.6 \pm 17.8$ & $58.8 \pm 14.1$ & NS & & & \\
\hline Gender & & & & & & & \\
\hline Male (\%) & $22(44 \%)$ & $45(54 \%)$ & $10(48 \%)$ & NS & & & \\
\hline \multicolumn{8}{|l|}{ Underlying diseases } \\
\hline None & $17(34.0)$ & $46(54.8)$ & $3(14.3)$ & $<0.001$ & 0.02 & NS & 0.001 \\
\hline DM & $6(12.0)$ & $20(23.8)$ & $9(42.9)$ & NS $(0.081)$ & NS $(0.095)$ & 0.008 & NS $(0.081)$ \\
\hline Hypertension & $15(30.0)$ & $26(31.0)$ & $12(57.1)$ & 0.025 & NS & 0.032 & 0.025 \\
\hline Chronic renal insufficiency & $1(2.0)$ & $4(4.8)$ & $5(23.8)$ & 0.015 & NS & 0.007 & 0.015 \\
\hline Hepatitis B infection & $2(4.0)$ & $5(6.0)$ & $1(4.8)$ & NS & NS & NS & NS \\
\hline Duodenal ulcer & $5(10.0)$ & $3(3.6)$ & $2(9.5)$ & NS & NS & NS & NS \\
\hline Others & $4(8.0)$ & $10(11.9)$ & $4(19)$ & NS & NS & NS & NS \\
\hline
\end{tabular}

they usually have underlying diseases. To analyze whether these factors might contribute to the high mortality in dengue virus-infected elderly patients, a comparison was made for three groups, each matched by age and sex: firstly, the 21 fatal cases; secondly, 84 cases of DHF; and thirdly, 50 cases of DF. Their charts were retrospectively reviewed for clinical information and laboratory data. By comparing the fatal cases with the non-fatal DHF cases, the ratio with hypertension and chronic renal insufficiency was significantly higher in fatal cases than in non-fatal DHF. The difference between fatal DHF and DF was also significant (Table 2). The ratio of diabetic mellitus was also higher between fatal and non-fatal DHF, although not reaching the 0.05 significant level $(\mathrm{p}=0.081)$. However, the fatal DHF group had a significantly higher ratio of diabetic mellitus than the DF group $(p=0.008)$. Other underlying diseases, including hepatitis B infection, duodenal ulcer, asthma, stroke and gout were not significantly different. The elderly dengue patients with certain underlying diseases seemed to develop a more severe disease after dengue virus infection.

We further compared the sequential data of DHF/DSS patients after hospitalization. As shown in Table 3, for DF or DHF, although the platelet count continued dropping and APTT and PT would be prolonged during the disease process, these would spontaneously return to normal in due course. However, for fatal cases, the platelet count changes, APTT and PT prolongation progressed to an irreversible state that 
Am. J. Infect. Dis., 4 (1): 10-17, 2008

Table 3: Multiple clinical parameter comparison in patients with DF, DHF/DSS and fatal cases

\begin{tabular}{|c|c|c|c|c|c|c|c|}
\hline Clinical parameter & $\begin{array}{l}{ }^{\mathrm{a}} \mathrm{DF} \\
(\text { Mean } \pm \mathrm{SD})\end{array}$ & $\begin{array}{l}{ }^{\mathrm{b}} \mathrm{DHF} / \mathrm{DSS} \\
(\mathrm{Mean} \pm \mathrm{SD})\end{array}$ & $\begin{array}{l}{ }^{\mathrm{c}} \text { Death case } \\
(\text { Mean } \pm \text { SD) }\end{array}$ & p@ & \multicolumn{3}{|c|}{ Post hoc } \\
\hline$\overline{\text { Platelet } 1^{*}(\mu \mathrm{L})}$ & $53696 \pm 50834$ & $31786 \pm 32476$ & $62812 \pm 54380$ & 0.001 & \multicolumn{3}{|c|}{$c>b, a>b$} \\
\hline Platelet $2 *(\mu \mathrm{L})$ & $60999 \pm 41707$ & $28259 \pm 6846$ & $42287 \pm 36840$ & $<0.001$ & \multicolumn{3}{|l|}{$a>b$} \\
\hline Platelet $3 *(\mu \mathrm{L})$ & $109026 \pm 49277$ & $96896 \pm 43322$ & $52283 \pm 36287$ & $<0.001$ & \multicolumn{3}{|c|}{$\mathrm{b}>\mathrm{c}, \mathrm{a}>\mathrm{c}$} \\
\hline APTT $1(\mathrm{sec})$ & $45 \pm 10$ & $52 \pm 12$ & $69 \pm 25$ & $<0.001$ & \multicolumn{3}{|c|}{$c>a, c>b$} \\
\hline APTT 2 (sec) & $37 \pm 9$ & $52 \pm 15$ & $81 \pm 35$ & $<0.001$ & \multicolumn{3}{|c|}{$\mathrm{c}>\mathrm{a}, \mathrm{b}>\mathrm{a}, \mathrm{c}>\mathrm{b}$} \\
\hline APTT $3(\mathrm{sec})$ & $33 \pm 5$ & $35 \pm 9$ & $84 \pm 36$ & $<0.001$ & \multicolumn{3}{|c|}{$c>a, c>b s$} \\
\hline PT 1 (sec) & $11 \pm 1.0$ & $12.1 \pm 4.4$ & $13.8 \pm 3.3$ & NS & & & \\
\hline PT 2 (sec) & $11 \pm 0.7$ & $11.3 \pm 1.3$ & $20.0 \pm 10.0$ & $<0.001$ & \multicolumn{3}{|c|}{$c>a, c>b$} \\
\hline \multirow[t]{2}{*}{ PT $3(\mathrm{sec})$} & $10.6 \pm 0.9$ & $10.9 \pm 1.0$ & $33.8 \pm 21.8$ & $<0.001$ & \multicolumn{3}{|c|}{$c>a, c>b$} \\
\hline & ${ }^{\mathrm{a}} \mathrm{DF}(\%)$ & ${ }^{\mathrm{b}} \mathrm{DHF} / \mathrm{DSS}(\%)$ & ${ }^{\mathrm{c}}$ Death case $(\%)$ & a-b-c p & $\mathrm{a}-\mathrm{b} \mathrm{p}^{\#}$ & $a-c p^{\#}$ & b-c p ${ }^{\#}$ \\
\hline $\mathrm{WBC}>10000 / \mu \mathrm{L}, 1$ & $2 / 49(4.1)$ & $4 / 84(4.8)$ & $2 / 21(9.5)$ & NS & NS & NS & NS \\
\hline 2 & $2 / 41(4.9)$ & $5 / 80(6.3)$ & $9 / 19(47.7)$ & $<0.001$ & NS & $<0.001$ & $<0.001$ \\
\hline 3 & $4 / 43(9.3)$ & $2 / 72(2.8)$ & $9 / 16(56.3)$ & $<0.001$ & NS & $<0.001$ & $<0.001$ \\
\hline НCT $<30 \%$, & $1 / 48(2.1)$ & $1 / 81(1.2)$ & $3 / 21(14.3)$ & 0.01 & NS & NS & 0.027 \\
\hline 2 & $3 / 42(7.1)$ & $4 / 76(5.3)$ & $8 / 20(40)$ & $<0.001$ & NS & 0.003 & $<0.001$ \\
\hline 3 & $2 / 42(4.8)$ & $8 / 73(11.0)$ & $10 / 16(62.5)$ & $<0.001$ & NS & $<0.001$ & $<0.001$ \\
\hline $\mathrm{AST}>1000 \mathrm{U} / \mathrm{L}, \quad 1$ & $0 / 43(0)$ & $7 / 64(10.9)$ & $5 / 16(31.5)$ & 0.001 & 0.04 & $<0.001$ & NS \\
\hline 2 & $0 / 7(0)$ & $3 / 31(9.7)$ & $8 / 15(53.3)$ & 0.001 & NS & 0.022 & 0.002 \\
\hline 3 & $0 / 2(0)$ & $0 / 15(0.0)$ & $5 / 6(83.3)$ & $<0.001$ & NS & NS & 0.001 \\
\hline ALT $>1000 \mathrm{U} / \mathrm{L}, 1$ & $0 / 36(0)$ & $1 / 67(1.5)$ & $4 / 15(26.7)$ & $<0.001$ & NS & 0.005 & 0.003 \\
\hline 2 & $0 / 8(0)$ & $2 / 31(6.5)$ & $4 / 13(30.8)$ & 0.038 & NS & NS & NS \\
\hline 3 & $0 / 2(0)$ & $1 / 13(7.7)$ & $4 / 6(66.7)$ & 0.014 & NS & NS & 0.017 \\
\hline $\mathrm{BUN}>30 \mathrm{mg} / \mathrm{dl}, \quad 1$ & $2 / 20(10.0)$ & $10 / 53(18.9)$ & $9 / 16(56.3)$ & 0.002 & NS & 0.004 & 0.008 \\
\hline 2 & $0 / 4(0)$ & $3 / 16(18.8)$ & 9/12 (75.0) & 0.002 & NS & 0.019 & 0.003 \\
\hline 3 & $0 / 5(0)$ & $0 / 5(0.0)$ & $9 / 10(90.0)$ & 0.002 & NS & NS & 0.002 \\
\hline
\end{tabular}

\#, Chi-square test; @, ANOVA, *The sampling time: 1, administration day 0-1/fever onset day 3-4; 2, administration day 2-3/fever onset day 5-6; 3, administration day 5-6/fever onset day 8-9, APTT, activated partial thromboplastin time; PT, prothrombin time; WBC, white blood cell; HCT, hematocrit; AST, aspartate aminotransferase; ALT, alanine aminotransferase; BUN, blood urea nitrogen

Table 4: Primary or secondary dengue infection in patients with DF, DHF/DSS and fatal cases

\begin{tabular}{llll}
\hline Type & Primary $(\%)$ & Secondary $(\%)$ & $\mathrm{p}^{\#}$ \\
\hline DF $(\mathrm{n}=1,560)$ & $395(25.3)$ & $1,165(74.7)$ & 0.18 \\
DHF/DSS $(\mathrm{n}=83)$ & $14(16.9)$ & $69(83.1)$ & $6(85.7)$ \\
Fatal case $(\mathrm{n}=7)$ & $1(14.3)$ & $1,240(75.2)$ & \\
Total & $410(24.8)$ & & \\
\hline
\end{tabular}

\#, Chi-square test

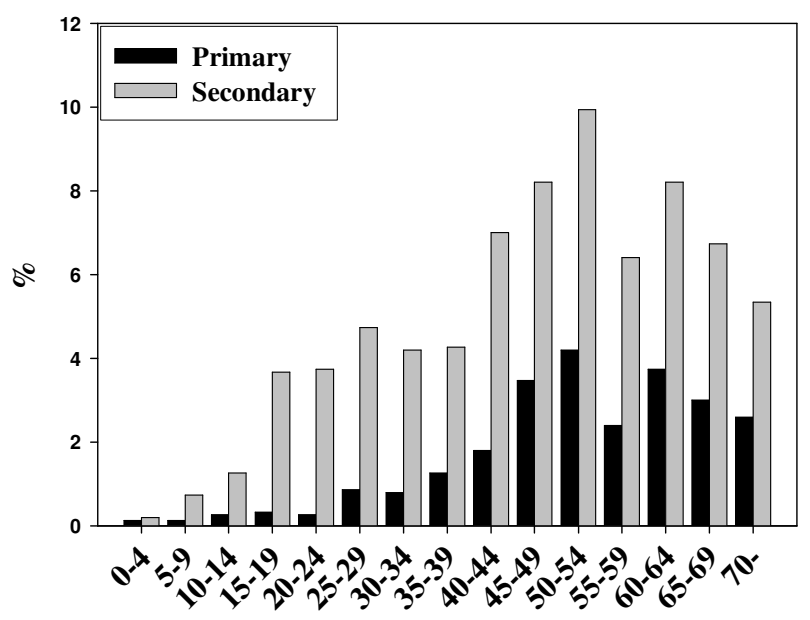

Age in years

Fig. 2: Age-specific prevalence of primary and secondary dengue infection in 2002 Kaohsiung dengue outbreak. The percentage of primary and secondary dengue virus infection was plotted against the age of 5 years 
resulted in death. When comparing the criteria of WBC $\left(>10,000 \mu \mathrm{L}^{-1}\right)$, hematocrit $(<30 \%)$, AST $\left(>1,000 \mathrm{U} \mathrm{L}^{-1}\right)$, or BUN (>30 $\mathrm{mg} \mathrm{mL}^{-1}$ ) among the DF group, the nonfatal DHF/DSS group and the fatal group, it was observed that higher levels of circulating leukocytosis, low hematocrit, hepatocyte damage and renal dysfunction were found in fatal cases than in nonfatal DHF/DSS. Furthermore, the status of the primary or secondary infection in this outbreak was shown in Table 4. A higher frequency of secondary infection was found for DHF/DSS than for DF groups, although it should be noted that primary dengue virus infection in adults can still cause DHF/DSS or even death. The age-specific prevalence of primary and secondary dengue virus infection also revealed that dengue virus infected primarily adults and more percentage of secondary infection than that of primary one (Fig. 2). Taken together, this suggests that a sustained inflammatory response and organ or tissue damages occurred post dengue, especially secondary, infection and this might have contributed to the death of these elderly patients with underlying diseases.

\section{DISCUSSION}

Following a retrospective analysis of clinical and laboratory data for DF, DHF/DSS and fatal cases in the 2002 Kaohsiung dengue outbreak, development into a severe form of the disease or death of dengue-infected patients was associated with the following conditions: elders with secondary infection and underlying diseases of hypertension, chronic renal insufficiency, or diabetes; abnormal hematological data and elevation of AST, ALT, BUN level during acute phase of infection. In a non-endemic area such as Taiwan, dengue is an adult infectious disease and the dengue-infected elders who have underlined diseases will develop into severe DHF/DSS or even death.

The age distribution pattern of our dengue patients is quite different from the average for South-East Asia, in which most of the cases are children. The ratio of DF progressing to $\mathrm{DHF} / \mathrm{DSS}$ is $4.5 \%$, similar to the estimated $6 \%$, but the case fatality rate of DHF was $8.7 \%$, significantly higher than the $<1 \%$ average figure for South-East Asia or Latin America ${ }^{[9,16-18]}$. In hyperendemic area, where there is concurrent transmission of all four serotypes, symptomatic dengue generally occurs during secondary dengue virus infections in school-age children or young adults. Although there were geographic and temporal variation in the incidence of dengue virus infection and disease in children, the burden of dengue is these hyperendemic area is substantial, with 22-292 per 1000 children infected per year. Furthermore, in children admitted to hospital, case-fatality rates is around $0.2-3.7 \%$ depending on the study population of the age and disease severity ${ }^{[9]}$. Dengue disease is known to be a childhood disease and the DHF is an important cause of pediatric hospitalization in southeast Asia. However, there is a change of increasing incidence of DHF among older age groups or adults ${ }^{[19-21]}$. In Taiwan, the epidemiological data showed that the initial dengue outbreak have always originated abroad, primarily being imported by travelers returning from South-East Asia, then spreading out later ${ }^{[22]}$. In countries where dengue currently is not endemic but where a capable vector exists, new autochthonous cycles of infection may be established from infected travelers or immigrants who are coming from areas where the disease is endemic; this phenomenon has been recently reported in Hawaii and Brazil ${ }^{[2,24]}$. The first outbreak of DHF in Bangladesh also showed the primarily affected population is the adults ${ }^{[25]}$. In our 2002 Kaohsiung outbreak, the dengue-infected symptomatic persons are primarily adults or elders with dengue serotype 2. A large outbreak was also recorded between 1987 and 1988 in the same area, which was caused by dengue serotype $1^{[26]}$. Secondary infection with a different serotype of dengue virus seems to contribute the development of DHF/DSS in this outbreak.

Dengue virus infection causes intense immune activation ${ }^{[27,28]}$. Aberrant immune responses such as cytokine overproduction and generation of autoantibody acting against platelets and endothelial cells occur after dengue virus infection. A molecular mimicry between platelets or endothelial cells with the NS-1 or prM of dengue virus would explain the crossreactive of anti-NS1 or anti-prM antibody to host cells $^{[29-31]}$ and might participate in the attack of platelet and endothelial cells during the disease development. We have proposed an immunopathogenesis hypothesis, which entails the autoimmunity induced by dengue virus, to explain the development of $\mathrm{DHF} / \mathrm{DSS}^{[32,33]}$. This hypothesis of autoantibody-associated immunopathogenesis needs further study. However, the anti-NS1 and anti-prM cross-reactive antibody induced attack on platelets and endothelial cells would provide an explanation for the unique feature of thrombocytopenia and plasma leakage in DHF/DSS. In children with DHF/DSS, the clinical manifestations usually resolve within 6-8 days after fever onset. The fever duration in Vietnam is around 5-6 days, irrespective of the condition being DF or DHF/DSS ${ }^{[28]}$. However, in DHF/DSS adults, the symptoms will last more than 10 days. In our experience on the 1998 Tainan dengue outbreak, we have learned that the 
duration from fever onset to defervescence in DHF/DSS patients was $11.38 \pm 4.6$ days $(n=8)$, which was longer than that in DF patients, with a duration of $5.38 \pm 1.66$ days $(n=13)^{[32]}$. In the adult DHF/DSS fatal case, leukocytosis (WBC>10000 $\mu^{-1}$ ) was observed, instead of leukopenia in children dengue. This might reflect that the dengue virus-caused DHF/DSS in the adult seems to have sustained disease process, which might be related to their underlying disease conditions and caused the extended duration of fever.

The experience of high fatality of DHF in Taiwan has lessons for other non-endemic areas. The major population to be infected by the dengue virus-carrying mosquito will be adults. The elders commonly suffer underlying diseases and will thus be more susceptible to progressive clinical symptoms resulting in death. The hypothesis of autoantibody-associated immunopathogenesis after acute dengue virus infection may shed light on the understanding of DHF/DSS pathogenesis. The clinician therefore needs to be trained to diagnose as early as possible and be experienced in fluid replacement treatment, especially as an inappropriate treatment can exaggerate the disease progression that contain an autoantibody-participated inflammation and lead to high mortality.

\section{CONFLICT OF INTEREST STATEMENT}

We declare that we have no conflict of interest.

\section{ACKNOWLEDGMENTS}

This study was supported by grant DOH92-DC1118 from the Department of Health, NHRI-CNCL9303P from the National Health Research Institute and grant NSC94-3112-B006-005 from National Science Council, Taiwan.

\section{REFERENCES}

1. Bhamarapravati, N., P. Tuchinda and V. Boonyapaknavik, 1967. V. Pathology of Thailand haemorrhagic fever: A study of 100 autopsy cases. Ann. Trop. Med. Parasitol., 61: 500-510.

2. Burke, D.S., A. Nisalak, D.E. Johnson and R.M. Scott, 1988. A prospective study of dengue infection in Bangkok. Am. J. Trop. Med. Hyg., 38: 172-180.

3. Wills, B.A., N.M. Dung, H.T. Loan, D.T.H. Tam, T.T.N. Thuy, L.T.T. Minh, T. V. Diet, N.T. Hao, N.V. Chau, K. Stepniewska, N.J. White and J.J. Farrar, 2005. Comparison of three fluid solutions for resuscitation in dengue shock syndrome. N. Engl. J. Med., 353: 877-889.
4. Guzman, M.G. and G. Kouri, 2002. Dengue: An update. Lancet Infect. Dis., 2: 33-42.

5. Mackenzie, J.S., D.J. Gubler and L.R. Petersen, 2004. Emerging flaviviruses: The spread and resurgence of Japanese encephalitis, West Nile and dengue viruses. Nat. Med., 10: S98-S109.

6. Guha-Sapir, D. and B. Schimmer, 2005. Dengue fever: New paradigms for a changing epidemiology. Emerg. Themes Epidemiol., 73: 1-10.

7. Gubler, D.J., 2002. Epidemic dengue/dengue hemorrhagic fever as a public health, social and economic problem in the $21 \mathrm{st}$ century. Trend Microbiol., 10: 100-103.

8. Halstead, S.B., 2005. More dengue, more questions. Emerg. Infect. Dis., 11: 740-741.

9. Deen, J.L., E. Harris, E.B. Wills B.A. Balmaseda, S.N. Hammond, C. Rocha, N.M. Dung, N.T. Hung, T.T. Hien and J. Farrar, 2006. The WHO dengue classification and case definitions: Time for a reassessment. Lancet, 368: 170-173.

10. Epidemiology Bulletin, Center for Disease Control, Department of Health, Taiwan, 2003; 19:16.

11. Liu, J.W., B.S. Khor, C.H. Lee, I.K. Lee, R.F. Chen and K.D. Yang, 2003. Dengue hemorrhagic fever in Taiwan. Dengue Bulletin, 27: 19-24.

12. Lai, P.C., S.S.J. Lee, C.H. Kao, Y.S. Chen, C.K. Huang, W.R. Lin, S.R. Wann, H.H. Lin, M.Y. Yen and Y.C. Liu, 2004. Characteristics of a dengue hemorrhagic fever outbreak in 2001 in Kaohsiung. J. Microbiol. Immunol. Infect., 37: 266-270.

13. Lee, M.S., K.P. Hwang, T.C. Chen, P.L. Lu and T.P. Chen, 2006. Clinical characteristics of dengue and dengue hemorrhagic fever in a medical center of southern Taiwan during the 2002 epidemic. J. Microbiol. Immunol. Infect., 39: 121-129.

14. World Health Organization (WHO), 1997. Dengue hemorrhagic fever: Diagnosis, treatment, prevention and control. 2nd Edn. Geneva: WHO.

15. Shu, P.Y., L.K. Chen, S.F. Chang, Y.Y. Yueh, L. Chow, L.J. Chien, C. Chin, T.H. Lin and J.H. Huang, 2003. Comparison of capture immunoglobulin $\mathrm{M}(\mathrm{IgM})$ and $\operatorname{IgG}$ enzyme-linked immunosorbent assay (ELISA) and nonstructural protein NS1 serotype-specific IgG ELISA for differentiation of primary and secondary dengue virus infections. Clin. Diagn. Lab. Immunol., 10: 622-630.

16. Shepard, D.S., J.A. Suaya, S.B. Halstead, M.B. Nathan, D.J. Gubler, R.T. Mahoney, D.N.C. Wang and M.I. Meltzer, 2004. Costeffectiveness of a pediatric dengue vaccine. Vaccine, 22: 1275-1280. 
17. Graham, R.R., M. Juffrie, R. Tan, C.G. Hayes, I. Laksono, C. Maroef, E. Sutaryo, K.R. Porter and S.B. Halstead, 1999. A prospective seroepidemiologic study on dengue in children four to nine years of age in Yogyakarta, Indonesia: I, studies in 1995-1996. Am. J. Trop. Med. Hyg., 61: 412-419.

18. Endy, T.P., S. Chunsuttiwat, A. Nisalak, D.H. Libraty, S. Green, A.L. Rothman, D.W. Vaughn and F.A. Ennis, 2002. Epidemiology of inapparent and symptomatic acute dengue virus infection: A prospective study of primary school children in Kamphaeng Phet, Thailand. Am. J. Epidemiol., 156: 40-51.

19. Wichman, O., S. Hongsiriwon, C. Bowonwatanuwong, K. Chotivanich, Y. Sukthana and S. Pukrittayakamee, 2004. Risk factors and clinical features associated with severe dengue infection in adults and children during the 2001 epidemic in Chonburi, Thailand. Trop. Med. Int. Health, 9: 1022-1029.

20. Porter, K.R., C.G. Beckett, H. Kosasih, R.I. Tan, B. Alisjahbana, P.I.F. Rudiman, S. Widjaja, E. Listiyaningsih, C. N. Maroef, J.L. Mcardle, I. Parwati, P. Sudjana, D. Yuwono and S. Wuryadi, 2005. Epidemiology of dengue and dengue hemorrhagic fever in a cohort of adults living in Bandung, West Java, Indonesia. Am. J. Trop. Med. Hyg. 72: 60-66.

21. Hammond, S.N., A. Balmaseda, L. Perez, Y. Tellez, S.I. Saborio, J.C. Mercado, E. Videa, Y. Rodriguez, M.A. Perez, R. Cuadra, S. Solano, J. Rocha, W. Idiaquez, A. Gonzalez and E. Harris, 2005. Differences in dengue severity in infants, children and adults in a 3-year hospital-based study in Nicaragua. Am. J. Trop. Med. Hyg., 73: 1063-1070.

22. Lei, H.Y., J.H. Huang, K.J. Huang and C.M. Chang, 2002. Current status of dengue control program in Taiwan -2001. Dengue Bulletin, 26: $14-23$.

23. Effler, P.V., L. Pang, P. Kitsutani, V. Vorndam, M. Nakata, T. Ayers, J. Elm, T. Tom, P. Reiter, J.G. Rigau-Perez, J.M. Hayes, K. Mills, M. Napier, G.G. Clark and D.J. Gubler, 2005. Dengue fever, Hawaii, 2001-2002. Emerg. Infect. Dis., 11: 742-748.
24. Nogueira, R.M.R., H.G. Schatzmayr, A.M.B. de Filippis, F.B. dos Santos, R.V. da Cunha, J.O. Coelho, et al., 2005. Dengue virus type 3, Brazil, 2002. Emerg. Infect. Dis., 11: 1376-1381.

25. Rahman, M., K. Rahman, A.K. Siddque, S. Shoma, A.H.M. Kamal, K.S. Ali, A. Nisaluk and R.F. Breiman, 2002. First outbreak of dengue hemorrhagic fever, Bangladesh. Emerg. Infect. Dis., 8: 738-740.

26. Liu, H.W., T.L. Ho, C.S. Hwang and Y.H. Liao, 1989. Clinical observations of virologically confirmed dengue fever in the 1987 outbreak in southern Taiwan. Kaohsiung J. Med. Sci., 5: 42-49.

27. Liu, C.C., K.J. Huang, Y.S. Lin, T.M. Yeh, H.S. Liu and H.Y. Lei, 2002. Transient CD4/CD8 ratio inversion and immune deviation during dengue virus infection. J. Med. Virol., 68: 241-252.

28. Hung, N.T., H.Y. Lei, N.T. Lan, Y.S. Lin, K.J. Huang, L. B. Lien, C.F. Lin, T.M. Yeh, D.Q. Ha, V.T.Q. Huong, L.C. Chen, J.H. Huang, L.T. My, C.C. Liu and S.B. Halstead, 2004. Dengue hemorrhagic fever in infants: A study on clinical and cytokine profiles. J. Infect. Dis., 189: 221-232.

29. Huang, K.J., S.Y.J. Li, S.C. Chen, H.S. Liu, Y.S. Lin, T.M. Yeh, C.C. Liu and H.Y. Lei, 2000. Manifestation of thrombocytopenia in dengue -2virus-infected mice. J. Gen. Virol., 81: 2177-2182.

30. Lin, C.F., H.Y. Lei, C.C. Liu, H.S. Liu, T.M. Yeh, S.T. Wang, T.I. Yang, F.C. Sheu, C.F. Kuo and Y-S. Lin, 2001. Generation of IgM anti-platelet autoantibody in dengue patients. J. Med. Virol., 63: 143-149.

31. Huang, K.J., Y.C. Yang, Y.S. Lin, J.H. Huang, H.S. Liu, T.M. Yeh, S.H. Chen, C.C. Liu and H.Y. Lei, 2006. The dual-specific binding of dengue virus and target cells for the antibodydependent enhancement of dengue virus infection. J. Immunol., 176: 2825-2832.

32. Lei, H.Y., T.M. Yeh, H.S. Liu, Y.S. Lin, S.H. Chen and C.C. Liu, 2001. Immunopathogenesis of dengue virus infection J. Biomed. Sci., 8: 377-388.

33. Lin, C.F., S.W. Wan, H.J. Cheng, H.Y. Lei and Y.S. Lin, 2006. Autoimmune pathogenesis in dengue virus infection. Viral Immunol., 19: 127-132. 